\title{
Method to Support Decision Making Process Considering Risk Factors
}

\author{
Gustavo BASTCHEN ${ }^{1}$ and Milton BORSATO \\ UTFPR - Universidade Tecnológica Federal do Paraná - Brazil
}

\begin{abstract}
The current scenario of the national and international market is marked by increasingly fierce competition and to ensure the survival of organizations, requires companies to develop new products cannot fail regarding cost, quality and time during a project. For this, the decisions that are made during the engineering changes of a product need to be assertive, taking into account factors of risk and concurrent engineering. The present work aimed to develop a new method to support the decision-taking process among multiple alternatives based on the evaluation of risk factors in the context of an engineering change. For this development, the Design Science Research was used as a methodological framework. The demonstration and evaluation steps were performed in the engineering environment of an automotive partner company. The solution developed was very pertinent to assist the decision-taking process, being able to provide more information and facilitate the evaluation of risk factors in the initial phases of the project. Also, it has been pointed out that, often, new artifacts applications need to be accompanied by a change in the mindset of organizations so that they can be effectively implemented.
\end{abstract}

Keywords. Engineering Changes, Multiple Alternatives, Product Development, Risk Management, Decision-Taking Process.

\section{Introduction}

Companies that develop new products are driven to respond in an increasingly fast and efficient way to survive in a market where competitiveness is increasing every day. In order to be able to face competition, the Product Development Process (PDP) has become indispensable for the organizations.

This process, according to [1], has a high degree of uncertainties and risks, because it is composed of countless variables from various sources of the company. For this complex and challenging scenario, according to [2], the lean product development has been presented as a success factor, whose revenue comes from the philosophy of "doing more with less". One of the principles that represent lean product development, according to [2], is to support the Set-Based Concurrent Engineering (SBCE) project systems with the aim of eliminating risks while learning is achieved using multiple alternatives. According [3], the application of this concept starts by considering a wide range of solution possibilities for the various systems, and then gradually reducing the number of solutions eliminating the "weakest" until convergence to the final solution is reached. In this way, the risk is reduced considerably through redundancy, robustness and knowledge capture.

Another success factor for this scenario is adequate risk management during the PDP. The development process of a product is always accompanied by several risk factors, usually due to lack of experience or knowledge about something [4]. Or, risk can be

\footnotetext{
${ }^{1}$ Corresponding Author. gbastchen@gmail.com
} 
considered as a deviation from what is expected that brings some uncertainty to the objectives, being positive, negative or both, and may create or result in opportunities and threats [5].

Some researches carried out in the last years stand out with the theme of improving the decision-taking process during the PDP. Methods have been developed to assist in this process. The study by [6] creates a method that analyzes the consequences of the decision taking into account only the impacts in two different criteria: cost and delay of schedule if a risk factor occurs but disregards the involvement of risk factors.

Also, mathematical models have been proposed to describe risks associated with qualitative and quantitative data. [7] propose the use of Bayesian networks to measure and monitor risks during the product development phase, combining the probability of occurrence, severity and loss if the risk occurs. Another study based on only a single solution proposal is from [8] that propose a model to support management decisions based on multicriteria, such as: marketing, project team, performance, risk and strategy. Again, the analysis of risk factors is excluded.

On the other hand, the authors [9] propose the creation of a model to assist in the evaluation and quantification of risk during the development process of complex products. This model assists in the simulation of risk propagation in order to support decision-taking. However, it does not take into account the use of multiple alternatives for risk assessment. Furthermore, [10] developed a framework and a method to aid decision-taking, using multiple alternatives in criteria such as risk and decision-taking. However, the study is applied to the manufacturing environment.

All of these researches point to the aid of the decision-taking process as a research trend, in order to improve the quality of the product developed and to reduce the probability of certain failures occurring for the final customer. Thus, this study follows the research trend identified in the recently published articles. In order to guide the decision-taking process by evaluating a set of risk factors that should be considered for a given product alternative in the context of an engineering change, this research developed a new method using the DSR framework. This method is detailed in this article, with an application example in an automotive industrial case.

\section{Theoretical Background}

This section is divided into 4 different subjects: engineering changes in the product development process, set-based concurrent engineering, risk management and decisiontaking process.

\subsection{Engineering changes in the PDP}

According to [11], Engineering Change (EC) is a change of a component of the product and occurs when it is already in the production phase. It can be further understood, according to [12], as modifications in parts, software or drawings already released during the project phase of the product. As for [13], it is characterized by changes in shapes, adjustments, functions, dimensions, materials, etc. of a product or a component and may occur at any stage in the product life cycle until the end of life.

A model found in the literature related to engineering changes within organizations is that of [12], and it's composed by 6 steps: reason identification, problem found, risk 
evaluation, approval process, timeplan for implementation, documentation and lesson learned record.

\subsection{Set-Based Concurrent Engineering}

The birth of the SBCE concept occurred shortly before Toyota's rise in the American automobile market, through [14], describing a development formed by a set of parallel alternatives that were reduced following engineering criteria during evolution from the project. It was in 1995 that this term was used to describe the approach of designers working on sets of solutions in parallel. The SBCE approach can be defined, according to [3] by means of three fundamental pillars, which are: mapping of the project space, integration by intersection and establishment of feasibility before signing commitment. Therefore, it is of great importance to the PDP to use more than one technical solution alternative in this stage of an engineering change, based on the SBCE. Thus, if some alternative offers a very high risk and the risk management strategy is to avoid this proposal, there are still other possibilities of solutions to be used.

For this, the uncertainties are monitored and controlled until the choice of the ideal technical solution using risk management. Thus, in spite of increasing the time needed to analyze different solutions, the SBCE approach indicates that risk management improves the quality of the solution adopted.

\subsection{Risk Management}

The project to develop a new product, due to its characteristics of complexity and multidisciplinarity, is frequently exposed to sources of risk, which according to [5] are elements that have the capacity to generate risks. Thus, according to [15], risk can be defined as the cumulative effect of the probability of uncertainty that can produce both a positive (opportunity) and negative (threat) outcome.

To avoid this negative effect, an adequate risk management should be used to obtain: aid in the decision process, precision of response, avoiding the propagation of a risk to other activities of the PDP. Managing risks is an iterative process and helps organizations establish strategies to achieve goals and make strategic decisions that take into account the external and internal contexts of the organization, as well as other aspects such as human behavior and cultural factors [5]. Risk management can be defined as a formal and systematic process that aims to identify, analyze, respond to, monitor and control project risks to meet its objectives such as scope, quality, time and cost [16]. Therefore, a desirable risk management is based on a proactive control of future events.

The next step is to characterize risk quantitatively. As an example, [17] propose a model to help measure the expected loss intensity by the occurrence of a risk factor. Then, the responses to risk factors are planned. Actions should be taken to reduce the effects on the project. Some ways to do this may be to avoid eliminating their cause, mitigate by reducing their probability and/or impact to an acceptable level, transferring the impact and responsibility to third parties, and accepting the impacts caused by adopting a reactive approach. Finally, it must monitor and control the risks to follow the results of the implementation of the actions, apply corrections to the responses, update probabilities and impact, monitor residual risks and identify new factors. This process must be run continuously in the project because they are dynamic and evolve over time. 


\subsection{Decision-taking process}

According to [18], the decision process is the transformation of a set of analyzed information into action, with the objective of applying the most convenient solution to solve a deadlock, as long as they satisfy the needs of the organization. In general, it consists of several elements, such as: doubts, risks, conditions of uncertainty, desired objective, conflicts, company strategy, and others.

For [19], a decision is the logical consequence of preferences, knowledge and the availability of options, that is, what is wanted, what is known and what can be done. The main steps of a decision-taking process are: problem identification, problem analysis, possible solutions, analysis and comparison of solution alternatives, selection of the most appropriate options, implementation of what was chosen and final evaluation. Many dayto-day decisions are made based on only one parameter, but when it comes to the area of product development, it must be admitted that they rarely fit into this situation because they have a more complex and multidisciplinary nature, involving many different parameters, and with this, can be characterized as a problem of Multicriteria Decision.

For this type of case, there is generally no alternative solution that is better for all criteria simultaneously. When this happens, we search for an option that has the best compromise among the various criteria analyzed according to the decision strategy [20]. To support this analysis, there are several solutions that help in this process, among them: Pugh Matrix, MDCA-C, AHP, PROMETHEE, and others.

\section{Methodological Aspects}

In the present work the methodological framework for prescriptive research proposed by [21] known as Design Science Research (DSR). According to [22], the DSR aims to study, research and investigate some problem and its respective behavior not only from the academic point of view, as well as from the organizational point of view. According to [23], the expected output is the solution of unresolved business problems with the creation of relevant artifacts.

For the present work, it was proposed to create a new method as artifact. The method definition is a set of steps used to execute a task [24]. The proposed method must be able to capture the structure of reality so that it may indeed be useful. For that, a case of industrial application of a company that develops new products was used. The first stage of DSR corresponds to problem identification and motivation. For this research, problem identification was performed on three different fronts. The first one was the diagnosis made from the analysis of documents, interviews and the researcher's own experience related to the root cause of the occurrence of quality problems in the product development area of an automotive partner company caused by engineering alterations. The second front was the alignment of the theme with one of the challenges proposed in the Intelligent Manufacturing Program, this being the demand 2 regarding Cost Analysis and Requirements Risk-Oriented. The third front was the bibliometric and systemic research carried out to identify the research gap [25].

In the second phase of the DSR, the expected objectives was the creation of an artifact to aid in the decision-taking process among multiple alternatives for a change of engineering, considering risk factors that take into account aspects not yet considered. The third phase, it was designed and developed the method. After the written 
construction of the method, the Bisagi editor was used as a tool to create the BPMN representation of the developed method. The fourth stage of the DSR framework was carried out on a partner company of the automotive branch that manufactures buses and trucks in the region of Curitiba in Brazil. The demonstration phase of the operation of the method occurred with the application of the same in a case of decision-taking among multiple alternatives for a change of engineering of the automotive area, more specifically for the change of the engine suspension of a heavy vehicle that presented quality problems. This registration occurred during tests of a prototype vehicle running on a test track, where the front cushion screw on the right side of the vehicle was lost in tightening and the front cushion was broken, while the left front cushion showed tightening loss and as shown in the side views of the vehicle shown in Figure 1.

Engine suspension of a heavy vehicle (buses and trucks) of this case had 4 attachment points: front right, left front, right rear and left rear. The cushions are the fixed parts on the structure (main frame) of the vehicle, while the engine brackets are fixed directly on the engine. To assemble front engine suspension, two screws were used transverse to the vehicle, as can be seen in Figure 2.

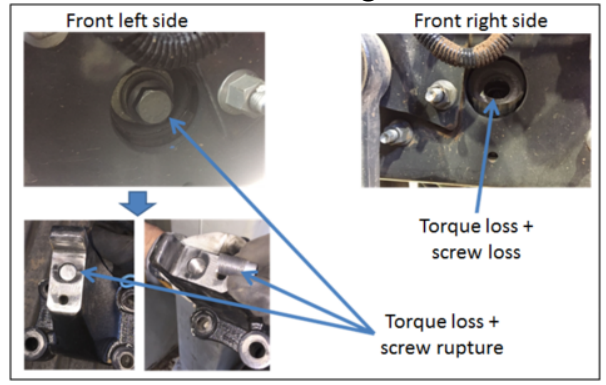

Figure 1. Quality problem of the demonstration case.

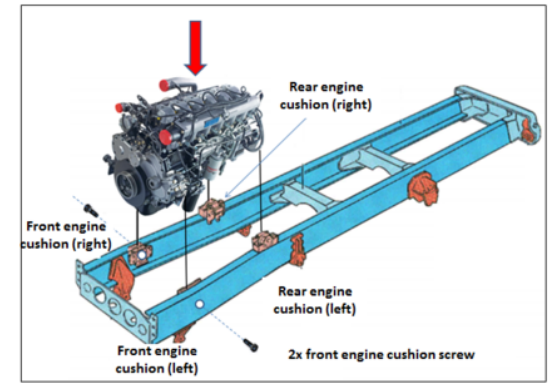

Figure 2. Heavy vehicle engine suspension example.

In this case of quality problem, the two front attachment points of the engine suspension could overload the two rear attachment points, resulting in a complete breakdown of the vehicle's engine assembly, which could lead to serious accidents if the vehicle was approved and released in such a manner. Thus, the quality problem should be addressed in order to completely solve the problem. Table 1 summarizes all 5 solution alternatives that were considered for this case.

\begin{tabular}{|c|c|c|c|c|c|}
\hline & Alternative 1 & Alternative 2 & Alternative 3 & Alternative 4 & Alternative 5 \\
\hline Engine bracket & Unchanged & Changed & Changed & Changed & New solution \\
\hline Cushion & Unchanged & Unchanged & Changed & Changed & New solution \\
\hline Screw & M16 & M18 & M18 & M18 dog point & New solution \\
\hline & & & & & \\
\hline
\end{tabular}

Table 1. Comparative summary of solution alternatives.

The fifth stage of DSR served to observe and measure how well the artifact assists in solving the identified problem, comparing the objectives of the solution with the results obtained from the demonstration phase. Thus, the purpose of this step is to answer the following question: does the proposed solution work well for the identified problem? The survey answered this question by evaluating some criteria. According to the forms 
proposed by [26], the evaluation technique considered is observational, since it uses a case study and its subsequent evaluation carried out in the context of a partner company that has a product development sector. A Google Forms online questionnaire composed of an explanatory video and questions was used as an evaluation tool. The data received from this questionnaire were compiled and analyzed to assess whether the solution solved the identified problem well.

The sixth stage of DSR is related to the unfolding of the knowledge produced by this research to the public in the area of product development and the academic community, in order to communicate the problem and its importance, the artifact developed, the usefulness and the novelty, the rigor of the project carried out and the effectiveness achieved by it in its application in the real world.

\section{Research Development}

A method was developed as an artifact. This method was called DSMMA (Decision Support Method for Multiple Alternatives), because it is related to decision support among multiple alternatives. The complete BPMN representation of the developed method can be seen in Figure 6. To simplify visualization and understanding, the method has been divided into 11 steps.

\subsection{Step 1 - Data Identification}

The first step includes all data collection activities, among which: (a) identify the opportunity for decision; (b) identify who are the decision makers or who will assist in the decision-taking; (c) identify the multiple solution alternatives; (d) identify the stakeholders' interests that are relevant areas/domains within a specific project; (e) what are the subinterests of the stakeholders within each area indicated in the previous item and that will serve as criteria for the analysis of the impact of the risks later.

One of the objectives of the research was to identify criteria besides the technical and commercial aspects, once these are more common to be identified and/or analyzed. The criteria group was constructed from several references, authors, books, standards, examples, and professional experiences of the author in the area of product development.

Then, each subinterest should be related to the impact value of the balancing matrix for each of the alternatives of the matrix of risk factors. The objective is to evaluate the impacts and probabilities of each one for each of the possible solution alternatives.

\subsection{Step 2 - Building the decision framework}

The second step builds a decision framework to be able to explicitly visualize the connection between all the items, that is, it facilitates to the participating members to visualize and to understand the objective of the decision, the interests of the other members and the available alternatives so that the best solution between them is chosen. It can be seen on the Figure 3 .

\begin{tabular}{|c|c|c|c|c|c|}
\hline \multirow{2}{*}{$\begin{array}{c}\text { Objective } \\
\text { Stakeholder's } \\
\text { interests }\end{array}$} & \multicolumn{5}{|c|}{ To select the best technical solution for the engine suspension problem. } \\
\hline & Technical & Organizational & Management & Comercial & Extern \\
\hline \multirow[b]{2}{*}{ Stakeholder's } & Reliability & Supportability & Project Management & Supplier stability & Concurrents \\
\hline & Platform & Personal availability & Ressources & Negotiability & \\
\hline \multirow[b]{2}{*}{$\begin{array}{c}\text { Solution } \\
\text { alternatives }\end{array}$} & Alternative 1 & Alternative 2 & Alternative 3 & Alternative 4 & Alternative 5 \\
\hline & No changes & New bracket & $\begin{array}{l}\text { New bracket } \\
\text { New cushion }\end{array}$ & $\begin{array}{l}\text { New bracket } \\
\text { New cushion } \\
\text { New screw }\end{array}$ & $\begin{array}{l}\text { Imported } \\
\text { solution }\end{array}$ \\
\hline
\end{tabular}

Figure 3. Decision framework example. 


\subsection{Step 3 - Building the risk impact balancing matrix}

In this step, the level of impact of the risk is balanced in order to reduce the sensitivity of the input data, as they directly affect the output data. This is done to prevent that, if two different people from the same department make the evaluation of the same item, they will arrive at different results for the same item.

As an example to illustrate this problem, one can cite a simple product change, such as a screw change of a technical solution, which risks increasing the cost of the product by less than $\mathrm{R} \$ 1$ being evaluated by two different buyers, being that one of them is responsible for the purchase of low cost parts (less than $\mathrm{R} \$ 1$ ) and the other for high cost parts (over R \$ 100). In making the same assessment of the impact of this risk, one of the buyers could assess the cost of the change as a high-impact threat (-5) and the other as a low-impact threat (-1). They would be evaluating the same item with different criteria, which could prevent the use of the method and arrive at a wrong decision. The balancing matrix is shown in Table 2 for the motor suspension used in this work, which defines the boundaries between a low, moderate and high impact for both opportunities (risks with positive impacts) and threats (risks with impacts negative).

\begin{tabular}{|c|c|c|c|c|c|c|c|c|}
\hline \multirow{2}{*}{\multicolumn{2}{|c|}{ Balancing matrix }} & \multicolumn{3}{|c|}{ THREAT } & \multirow{3}{*}{$\begin{array}{c}\text { N/A } \\
0\end{array}$} & \multicolumn{3}{|c|}{ OPPORTUNITY } \\
\hline & & HIGH & MEDIUM & LOW & & LOW & MEDIUM & HIGH \\
\hline TECHNICAL & SCALE & -5 & -3 & -1 & & 1 & 3 & 5 \\
\hline Reliability & $\begin{array}{c}\text { Fault } \\
\text { frequency }\end{array}$ & $\begin{array}{c}\text { Increase more } \\
\text { than } 0.005\end{array}$ & $\begin{array}{c}\text { Increase } \\
\text { until } 0.005\end{array}$ & $\begin{array}{c}\text { Increase less } \\
\text { than } 0.001\end{array}$ & N/A & $\begin{array}{l}\text { Reduce less } \\
\text { than } 0.001\end{array}$ & $\begin{array}{c}\text { Reduce } \\
\text { until } 0.005\end{array}$ & $\begin{array}{c}\text { Reduce more } \\
\text { than } 0.005\end{array}$ \\
\hline $\begin{array}{c}\text { Tooling } \\
\text { Investment }\end{array}$ & $\begin{array}{c}\text { x1000 Reais } \\
\text { (KRS) }\end{array}$ & $\begin{array}{c}\text { Increase more } \\
\text { than } 100 \mathrm{KR} \$\end{array}$ & $\begin{array}{c}\text { Increase } \\
\text { until }\end{array}$ & $\begin{array}{c}\text { Increase less } \\
\text { than } 1 \text { KRS }\end{array}$ & $\mathrm{N} / \mathrm{A}$ & $\begin{array}{c}\text { Reduce less } \\
\text { than 1KRS }\end{array}$ & $\begin{array}{c}\text { Reduce } \\
\text { until }\end{array}$ & $\begin{array}{l}\text { Reduce more } \\
\text { than } 100 \mathrm{KRS}\end{array}$ \\
\hline
\end{tabular}

Table 2. Risk impact balancing matrix example.

\subsection{Step 4 - Risk evaluation}

The impact level of each identified risk were evaluated according to the balancing matrix and also the probability was evaluated according to the following levels: rare, unlikely, unlikely, very likely and almost certain, taking the score values 1, 2, 3, 4 and 5 whose probability of occurrence is $10 \%, 30 \%, 50 \%, 70 \%$ and $90 \%$ respectively.

\subsection{Step 5 - Weight definition}

This step defines the weights for each of the criteria. The objective of this stage is to balance the level of impact with the level of contribution of each of the assessed aspects. This definition must be made by the project team, since it is they who will determine the strategy of the decision-taking in question. Although there are several evaluation criteria, each of them has a differentiated contribution level according to the established strategy. For example, for a cost reduction project, cost-related criteria will probably have a greater weight than the other criteria for this decision-taking. In order to carry out this step, the following sequence of activities is defined: reorganizing the list of stakeholder interests in descending order of importance for the decision in question, leaving the most relevant criteria on top, and the least relevant criteria below. Distribute a total score of 100 points between these criteria, the most relevant of which will have the highest weight and the least relevant will have a lower weight.

The next activity is to rearrange the list of stakeholders' subinterests in descending order within each interest in the same way as previously done. The weight of each subcriteria can be any number between zero and the value adopted for the criteria. For example, within the 'Technical' criteria with a value of 50, the sub-criteria 'Reliability/Safety' could have any weight between 0 and 50 . 


\subsection{Step 6 - Risk impact score calculation}

It is performed the calculation of the impact score. For this, it is enough to multiply the values assigned to the impacts of each of the risk factors identified by the weight of each related criteria.

\subsection{Step 7 - Creation of risk impact graphic representation}

Following the step of calculating the impact score, these data are used to feed the graphing step that represents the previously assessed impacts. This step is very important to: (a) compare the impact levels of one aspect in all alternatives; (b) compare the impact of each sub-criteria on a single alternative; (c) comparing the number of risks identified in each alternative and the contribution of each of these risks to the total impact of each alternative. The first graphic to be created shows a comparison of the impact of each aspect for all alternatives. For this representation, a radial type graph was chosen because it is capable of representing multiple alternatives, in the case of Figure 4, five alternatives were represented in the shape of a pentagon, but could be represented even more alternatives or less, valid for a comparison from two alternatives. The points indicated within the red pentagon are threats because they have risks with negative impacts while the points between the red and green pentagon are opportunities, that is, risks have a positive impact. The second graph shows the results of the impact of each of the risks of a single alternative (Figure 5). For this representation, a single column type graph was chosen, with variable 'Impact' represented on the y-axis, and the name of each risk on the $\mathrm{x}$-axis. The representation facilitates the comparison of the impact level for each of the risks of the same alternative.

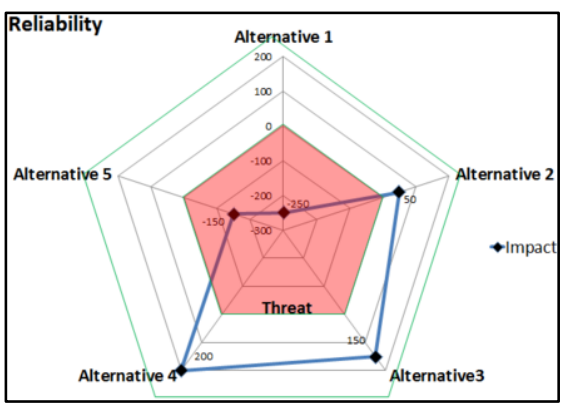

Figure 4. Impact representation for each alternative.

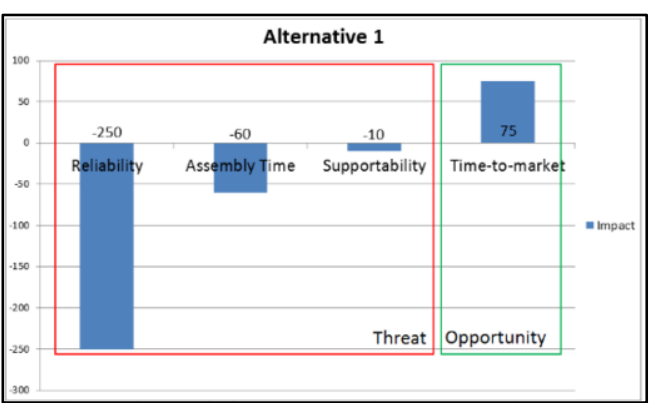

Figure 5. Impact representation comparative per alternative.

The third graph is able to represent the contribution of each of the risks to each alternative and allows to compare the overall impact result between the different alternatives, as well as to show the number of risks that were identified for each of the alternatives. It was used the stacked column type chart, in which, for each alternative, the impact score of all the risks are grouped on top of each other in order to visualize the overall comparison between all the alternatives. In the y-axis is represented the impact level, and in the x-axis, the different alternatives. Again this type of chart was adequate because there is no lower or higher limit on the number of alternatives or the number of 
risks that can be stacked in each of the columns. Threats are represented at the bottom of the chart while opportunities are represented at the top.

\subsection{Step 8 - Definition of the strategy for decision support}

The next step in this method is to use the results obtained to identify and define the strategy to aid in decision-taking, either by amplifying risks with positive impacts, mitigating those with negative impacts, or even eliminating very risky alternatives. You can perform this step using any of the three chart types shown above. For the example used in this work, in which the third type of graph was used to identify in Alternative 1 that one of the most relevant risks is the sub-criteria 'Reliability/Safety'. Since the risk has a fairly high negative impact, it was defined that it should be mitigated before the decision is made. Many actions could be taken in this case to reduce the risk, such as: testing the solution on the bench, performing other virtual simulations, performing a assembly of the set, among others. In alternative 3, it was identified that there is an opportunity to increase the impact factor of the 'Reliability/Safety' risk, which is positive. It was defined that it could be potentialized, that is, increase the impact of it. For this, the same actions could be defined as the previous example, but for opposite results.

\subsection{Step 9 - Integration of proposed method with the decision-making tool}

The purpose of the research is to develop a method to aid in the decision-taking process. This method is not intended for decision-taking in and of itself. Therefore, in this step, the integration of the developed method occurs with some method or tool of decision-taking that the company already uses in its process. In the example of this dissertation, the method was integrated with the PMA, due to its ease of use and wide use, but nothing prevents it from being integrated with other solutions that the company already uses and has more affinity for decision-taking, such as: MCDA-C, AHP, PROMETHEE and other possibilities.

\subsection{Step 10 - Use of results to support decision-making process}

After the integration stage with the company's decision-taking process, it is possible to use all the results obtained through the method to assist this process or even serve as a justification for postponing decision-taking. It is emphasized that it is more important that the decision made is correct than the time spent for this decision is short, because if the decision taken is incorrect, much more time and resources will be spent to correct it than if it was carried out at that moment.

\subsection{Step 11 - Creating/Updating the database}

The database serves as an alternative to feed some information during the use of the method, among them the matrix of interests and subinterest of stakeholders, the information of the balancing matrix, and others that can be used as a basis in the next decisions to be taken.

\subsection{Evaluation}

The method evaluation process consisted of a qualitative evaluation through the application of a questionnaire. The qualitative analysis corresponds to the characteristics of the object that are evaluated on a value basis that emphasizes the descriptive part of the same and not through a numerical basis in the case of a quantitative evaluation. A questionnaire was applied to a group of people related to the research area, such as mechanical engineers, product development engineers, project managers, engineering coordinators and master's students in the field of intelligent manufacturing. In the first submission of the form made on September $6^{\text {th }}, 2018$, and with the response deadline of 
1 week for 102 people, a percentage of responses of $20.6 \%$ was obtained. The main aspects evaluated were: efficiency, generality, ease of use, operability and utility.

The efficiency criteria resulted in $92.3 \%$, indicating that it works and works well for the proposed objective, which is to assist in the decision-taking process among multiple alternatives in an engineering change, in addition to the gain obtained by this process is easily noticeable. The generality aspect was also very well evaluated, reaching the result of $90.9 \%$, which indicates that this method can be applied in other contexts, in other products and in other companies to assist in the decision-taking process among multiple alternatives in a change of engineering. The ease of use aspect comprises the issues of ease of understanding and application of the new method. The result obtained by the evaluation process was $72 \%$. One suggestion to improve the result could be the development of a tool to assist this process.

For the operability criteria, the objective was to understand if it would be possible to apply this new method in the daily activities of the company and how operational it was. The result obtained in the evaluation of this criteria was $77.6 \%$, which indicates that it is possible to be applied to a decision-taking process among multiple alternatives in an engineering change. According to the reviewers' open comments, part of this is due to the inertia of the company's own process in adopting new practices that change the mindset and another part related to the need for further evidence that the method actually works before it can be applied in the company.

Another criteria needed to be evaluated in the method was that of utility, that is, if there is something that is done by it that could not be done previously without it. The result of this item was $85.5 \%$, showing that it is useful and that it is remarkable that the method presents some activities with a certain level of innovation for the process, contributing to justify its use. Some of the items pointed out in the research that supported in this question were: use of several already identified aspects that could have been neglected during the decision-taking process of multiple alternatives in the context of an engineering change and the use of graphics to aid in understanding the level of impact of some risks and contribution to the impact that that alternative could cause in the project. In addition, it was possible to use these graphs to amplify opportunities, mitigate threats, and eliminate very risky alternatives to the process, which was very useful since it was not possible in the traditional process.

Another highlighted point from the evaluation was the high number of recurrence in the open evaluation process regarding the balance between the use of the method and the available time. According to the evaluations made in the fields where the respondent could write his opinion openly, there were at least 10 occurrences in which there was mention of the increase of time spent using the method as something negative. This issue deserves a more in-depth discussion, because as essential as the development of artifacts (methods, frameworks, tools), it is necessary that its application be accompanied by a change of mindset so that it can be effective. 


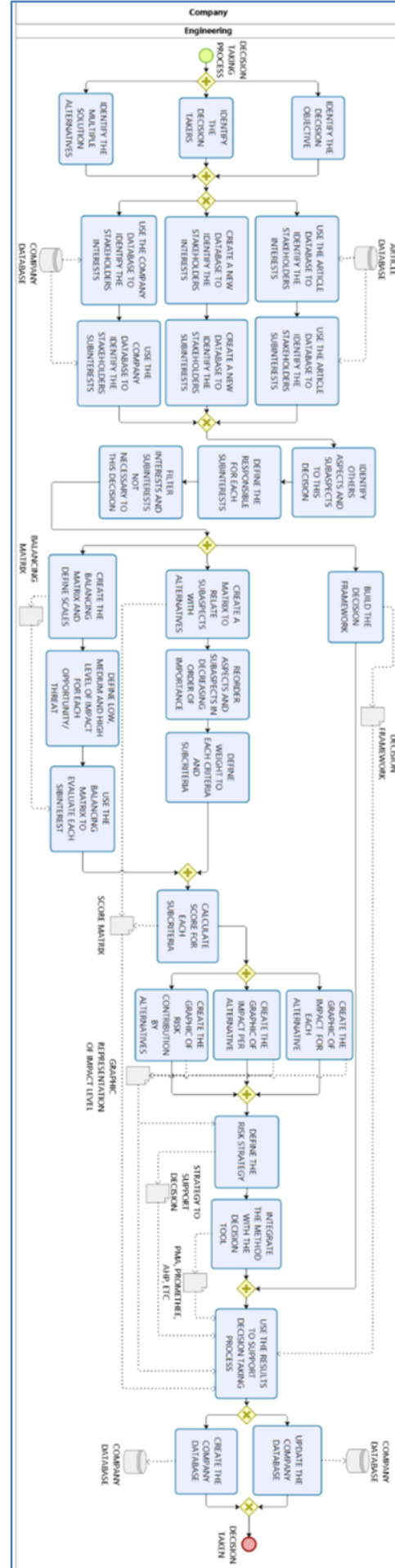

Figure 6. Complete method to support decision making process considering risk factors.

\section{Conclusions}

Despite the availability of solutions to aid the decision-taking and risk management process, companies still find it difficult to efficiently avoid quality problems resulting from risk factors that had not been considered in the early stages of design during engineering changes. In the demonstration stage, the developed method worked for the problem of quality of the suspension of a heavy vehicle, supporting the decision-taking among 5 different solution alternatives. In addition, it was possible to take into account many other risk factors that could have been neglected in a traditional decision-taking process. Since the method can be incorporated into other tools already used by the company for decision-taking, this facilitates its use as it becomes a small incremental improvement step in the process. It was also possible to reduce the sensitivity of the input data with the use of the balancing matrix, so that two different people would arrive at a similar result, if not identical. Furthermore, the possibility of graphically analyzing the degree of impact of risks among multiple alternatives was very relevant in this process and made it possible to potentialize opportunities, mitigate threats and eliminate very risky alternatives.

Already in the evaluation stage, the obtained result indicated that the developed method is efficient for making the process of decision-taking more consistent. In addition, the generality aspect indicated that the solution could be applied to other contexts, products or companies. Yet, the utility aspect has indicated that the new method is capable of delivering something more that could not be done without it. However, the result showed possibility of improvements to facilitate its application and be able to be operationalized in the problems of the day to day in product development. It was also possible to conclude that the application of new artifacts often needs to be accompanied by a change in the mindset of organizations so that they can be effectively implemented.

Given the limitations presented, it is suggested as recommendations of future work the development of a tool to apply the proposed method with the objective of making it easier to use and more 
operational. In addition, it is recommended that this method be applied to different industries, contexts, and products.

\section{References}

[1] H. Rozenfeld, F. Forcellini, D. Amaral, J. Toledo, S. Silva, D. Alliprandini and R. Scalice, Product development management: a reference to improve process (In Portuguese), São Paulo: 542p, EditoraSaraiva, 2006.

[2] A. Ward and D. Sobek II, Lean product and process development, Lean Enterprise Institute, p.82$128,2014$.

[3] D. Sobek, A. Ward and J. Liker, Toyota's principles of set-based engineering, Boston: Sloan Management Review, 1999.

[4] M. Neumann, M. Sporbeck, T. Sadek and B. Bender, A Model Based Approach to Support Risk Management in Innovation Projects. In: Modelling and Management of Engineering Processes, Springer, Berlin, Heidelberg, p. 35-46, 2015.

[5] ABNT NBRISO, ISO 31000 Risk Management: Principles and guidelines (In Portuguese), Committee Draft of ISO, v. 31000, 2009.

[6] F. Marmier, I. F. Deniaud and D. Gourc, Strategic decision-making in NPD projects according to risk: application to satellites design projects, Computers in Industry, 65(8), 1107-1114, 2014.

[7] A. Halabi; R. Kenett and L. Sacerdote. Using dynamic Bayesian networks to model technical risk management efficiency, Quality and Reliability Engineering International, 2017.

[8] M. Relich and P. Pawlewski, A fuzzy weighted average approach for selecting portfolio of new product development projects, Neurocomputing, v. 231, p. 19-27, 2017.

[9] N. Li, X. Li, Y. Shen, Z. Bi and M. Sun, Risk assessment model based on multi-agent systems for complex product design, Information Systems Frontiers, 17(2), 363-385, 2015.

[10] L. Shah, A. Etienne, A. Siadat and F. Vernadat, Decision-making in the manufacturing environment using a value-risk graph, Journal of Intelligent Manufacturing, p. 617-630, 2016.

[11] I. Wright, A review of research into engineering change management: implications for product design, Design Studies, 1997.

[12] T. A. W. Jarratt, C. M. Eckert and P. J. Clarkson, Engineering change, In: Clarkson PJ, Eckert CM (eds) Design process improvement, Springer, New York, 2004.

[13] G. Q. Huang and K. L. Mak, Current practices of engineering change management in UK manufacturing industries, International Journal of Operations \& Production Management, Vol. 19 Iss: 1, pp. $21-37,1999$.

[14] A. Ward, C. Allen and W. Seering, Quantitative inference in a mechanical design compiler, 1989.

[15] J. Schuyler, Risk and decision analysis in projects, Pennsylvania: Project Management Institut, 2001.

[16] PMI, Project Management Institute. A guide to the project management body of knowledge (PMBOK®Guide), Pennsylvania: Project Management Institut, 2018.

[17] P. Smith and G. Merritt, Proactive risk management. controlling uncertainty in product development, NY: P. Press, 2002.

[18] D. Oliveira, Informatic systems of strategic management information (In Portuguese), 13. ed. São Paulo: Atlas, 2010.

[19] F. M. Campello de Souza, Rational decisions in uncertainties situations (In Portuguese), Recife: Editora Universitária. 2007.

[20] M. Zeleny, Multiple Criteria Decision Making, New York: MacGraw-Hill. 1982.

[21] K. Peffers, T. Tuunanen, M. Rothenberger and S. Chatterjee, A design science research methodology for information systems research, Journal of management information systems, Abingdon, Reino Unido, v. 24, n. 3, p. 45-77, 2007.

[22] N. Bayazit, Investigating design: A review of forty years of design research, Design issues, v. 20, n. 1, p. 16-29, 2004.

[23] R. Von Alan, S. March, J. Park and S. Ram, Design science in information systems research, MIS quarterly, p. 75-105, 2004.

[24] A. Dresch, D. P. Lacerda and J. Júnior, Design science research: método de pesquisa para avanço da ciência e tecnologia: Bookman Editora, 2015.

[25] G. Bastchen, F. Silva and M. Borsato, Risk management analysis in the product development process, Procedia Manufacturing, v. 17, p. 507-514, 2018.

[26] A. Hevner and S. Chatterjee, Design science research in information systems, Design research in inf. systems: Springer, 2010. 